\title{
Microstructure and coercivity of granular FePt-AlN thin films
}

\author{
S.C. Chen*, P.C. Kuo, C.T. Lie, J.T. Hua \\ Institute of Materials Science and Engineering, National Taiwan University, Taipei, Taiwan
}

Received 14 November 2000; received in revised form 29 March 2001

\begin{abstract}
$(\mathrm{FePt})_{100-x}-(\mathrm{AlN})_{x}(x=0-50$ vol $\%)$ granular films were prepared by DC and RF magnetron co-sputtering of FePt and AlN targets, then annealed in vacuum at various temperatures. Transmission electron microscopy analysis shows that the structure of the film is granular FePt particles embedded in amorphous AlN matrix and the FePt particle in asdeposited film is face-centered-cubic $\gamma$-phase and in the high coercivity annealed film is face-centered-tetragonal $\gamma_{1}$ phase. The particle size of FePt in annealed film was increased with the annealing temperature and film thickness but decreased with increasing AlN content. The magnetic anisotropy of the film was parallel to the film plane. The coercivity of the FePt-AlN film was dependent on the annealing temperature, the AlN volume fraction, and film thickness. It was found that the optimum annealing temperature for obtaining highest coercivity of the film is increased with AlN content. The in-plane coercivity of the film could reach to about $8 \mathrm{kOe}$ for the $(\mathrm{FePt})_{70}-(\mathrm{AlN})_{30}$ film after annealing at $750^{\circ} \mathrm{C}$ for $30 \mathrm{~min}$. (C) 2001 Elsevier Science B.V. All rights reserved.
\end{abstract}

PACS: $75.50 . \mathrm{Bb} ; 75.70 . \mathrm{Ak} ; 75.50 . \mathrm{Ss} ; 75.50 . \mathrm{Tt}$

Keywords: Coercivity; FePt-AlN granular film; Magnetron co-sputtering

\section{Introduction}

The most important problem in magnetic recording media is how to increase the recording density of the media. Practically, if we want to increase the areal recording density of the magnetic recording thin film, the grain size of the film must be reduced. However, when the grain size of the film is smaller than the material's singledomain size, grains will become superparamagnetic particles. The grain size of the film is limited by the single-domain size. According to Stoner

\footnotetext{
*Corresponding author. Tel.: + 886-2-23648881; fax: + 8862-23634562.

E-mail address: sscchh@ms28.hinet.net (S.C. Chen).
}

Wohlfarth mode, we know that the single-domain critical size is inversely proportional to material's magnetic anisotropy constant [1]. Therefore, using high magnetic anisotropy constant material as recording film, the recording bits of the film can be reduced and recording density of the film will be increased. The ordered equiatomic $\gamma_{1}$-FePt phase with FCT structure Llo has very high magnetocrystalline anisotropy constant $\left(\mathrm{Ku} \cong 7 \times 10^{7} \mathrm{erg} /\right.$ $\mathrm{cm}^{3}$ ). It makes the $\gamma_{1}$-FePt grain has very small critical single-domain size. So, $\gamma_{1}$-FePt is suitable for high density magnetic recording material.

Furthermore, the magnetic grains in recording film must be separated to reduce the exchange interactions between grains in order to decrease medium noise. Various granular films with 
magnetic grains dispersed in non-magnetic matrix as recording media for higher density magnetic recording are proposed lately [1-6]. Since the magnetic particles in these granular films are isolated, the media noise of the films can be largely reduced. The granular media have many other good properties such as oxidization resistance, corrosion resistance and wear resistance due to the magnetic particles being surrounded by an insulator.

In this work, we prepare the granular FePt-AlN recording films by magnetron co-sputtering method and investigate the coercivity and microstructure of the film. The magnetic hardening mechanism of the film and the inter-particles interactions of $\mathrm{FePt}$ particles in granular $\mathrm{FePt}-$ AlN films are also discussed.

\section{Experiment}

$(\mathrm{FePt})_{100-x}-(\mathrm{AlN})_{x}(x=0-50 \mathrm{vol} \%)$ thin film were deposited on nature oxidized $\mathrm{Si}(100)$ substrates at room temperature by co-sputtering high purity $\mathrm{Fe}_{50} \mathrm{Pt}_{50}(99.99 \%)$ and $\mathrm{AlN}(99.95 \%)$ targets with DC and RF powers, respectively. The substrate is rotated at $75 \mathrm{rpm}$ in order to attain uniform composition of the film. The film thickness ranges from 10 to $100 \mathrm{~nm}$.

The base pressure of sputter chamber was approximately $5 \times 10^{-7}$ Torr and the films were deposited under an argon pressure of $7 \mathrm{mT}$ Torr. The adjustment of the power supplies of DC and RF sputtering guns provides a wide range of effective AlN volume fractions of the film. The DC power is fixed at $2 \mathrm{~W} / \mathrm{cm}^{2}$ and RF power is varied from 1.25 to $12.5 \mathrm{~W} / \mathrm{cm}^{2}$. The deposition rate of FePt was about $0.3 \mathrm{~nm} / \mathrm{s}$. The as-deposited film was sealed in quartz capsules and then post-annealed in vacuum at temperatures between $350^{\circ} \mathrm{C}$ and $850^{\circ} \mathrm{C}$ for $30 \mathrm{~min}$. The film was quenched in ice-water after annealing.

The structures of the films were analyzed by $\mathrm{X}$-ray diffractometer $(\mathrm{XRD})$ with $\mathrm{Cu}-\mathrm{K}_{\alpha}$ radiation. The film microstructure was observed by transmission electron microscopy (TEM) and the crystallographic structure was examined by electron diffraction analysis. Magnetic properties were measured by vibrating sample magnetometer (VSM) and superconducting quantum interference device (SQUID) at room temperature, with maximum applied fields were 13 and $50 \mathrm{kOe}$, respectively. The average grain size of the film was calculated from the TEM bright field image. Composition and homogeneity of the films were determined by energy disperse spectrum (EDS) and the film thickness was measured by a $\alpha$-step.

\section{Results and discussion}

Fig. 1(a) shows the TEM bright field image of the as-deposited $(\mathrm{FePt})_{70}-(\mathrm{AlN})_{30}$ film whose film thickness is $100 \mathrm{~nm}$. It indicates that the black

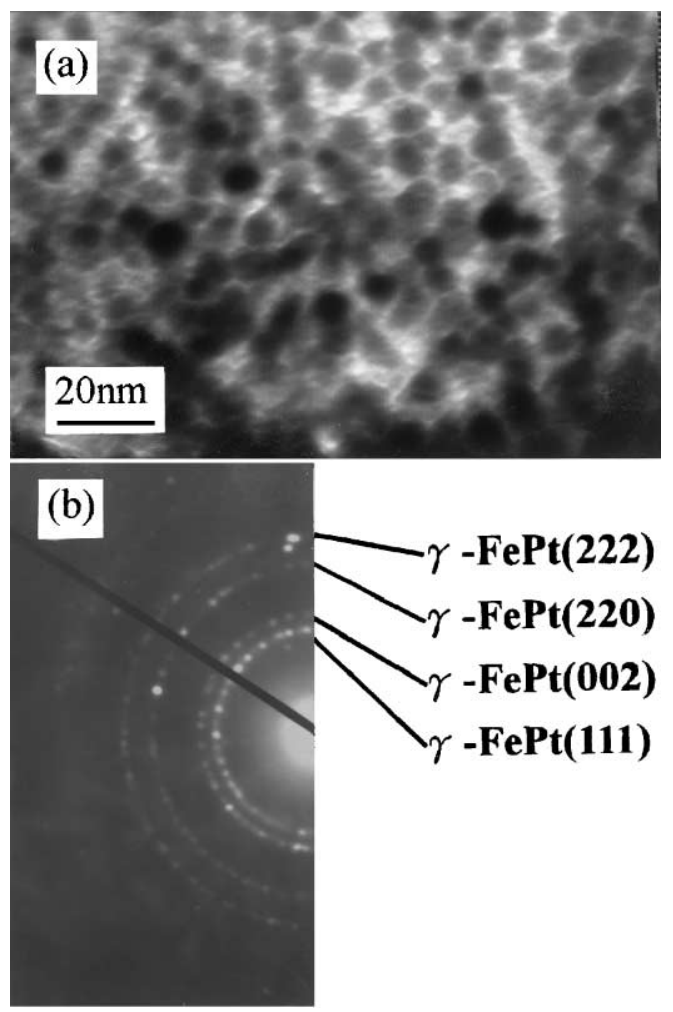

Fig. 1. Plane view TEM micrograph and electron diffraction pattern of the as-deposited $(\mathrm{FePt})_{70^{-}}(\mathrm{AlN})_{30}$ film. (a) The bright field image and (b) the selected area diffraction pattern of (a). 
FePt grains are dispersed in the white amorphous AlN matrix. The average particle size of the FePt grains is about $5 \mathrm{~nm}$. Fig. 1(b) is the selected area diffraction (SAD) pattern of Fig. 1(a). It shows that only the soft magnetic FCC $\gamma$-FePt crystal phase was found in the film, the AlN diffraction rings are not appeared. So, the $\mathrm{AlN}$ is an amorphous state in the as-deposited film.

Fig. 2 shows the X-ray diffraction patterns of pure $\mathrm{FePt}$ films, which annealed at various temperatures. The as-deposited film is $\gamma$-FePt phase. The superlattice peaks of $\gamma_{1}$-FePt phase are not clear as the annealing temperature is lower than $550^{\circ} \mathrm{C}$. Fig. 3 shows the X-ray diffraction patterns of various annealed composite $(\mathrm{FePt})_{70^{-}}$ $(\mathrm{AlN})_{30}$ films. We can see that the as-deposited film is also $\gamma$-FePt phase. However, the superlattice peaks of $\gamma_{1}-\mathrm{FePt}$ phase appear at much higher annealing temperature (about $650^{\circ} \mathrm{C}$ ) than that of pure FePt film. This indicates that the addition of $\mathrm{AlN}$ in the FePt film will increase the phase transformation temperature of $\gamma$-FePt to $\gamma_{1}$-FePt. We speculate that the $\gamma-\mathrm{FePt}$ particle in asdeposited $(\mathrm{FePt})_{70}-(\mathrm{AlN})_{30}$ film cannot be transformed to $\gamma_{1}$-FePt phase by quenching the film in ice-water after annealing below $600^{\circ} \mathrm{C}$, is due to the heat dissipation of AIN is lower than that of pure FePt metal and the FePt particle is constrained by the AlN matrix. Since the crystalline

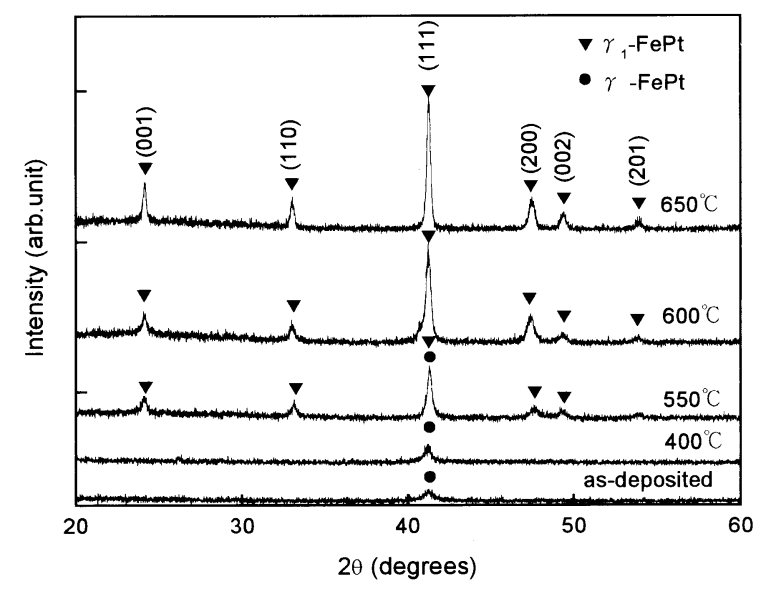

Fig. 2. X-ray diffraction patterns of the as-deposited and various annealed pure FePt films. The film thickness is $100 \mathrm{~nm}$.

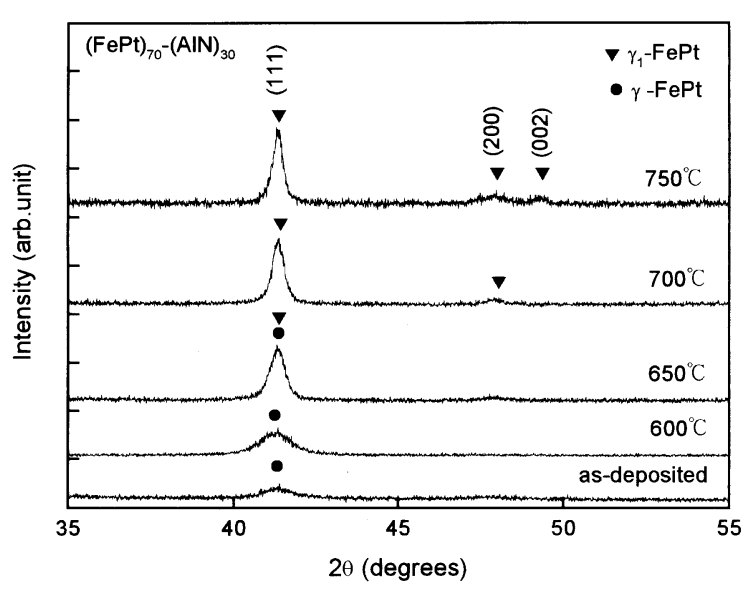

Fig. 3. X-ray diffraction patterns of the as-deposited and various annealed $(\mathrm{FePt})_{70}-(\mathrm{AlN})_{30}$ films. The film thickness is $100 \mathrm{~nm}$.

volume of FePt particle will be changed during the phase cooling rate and the crystalline volume of FePt is changed during phase transformation.

Fig. 4(a) shows the TEM bright field image of the $(\mathrm{FePt})_{70}-(\mathrm{AlN})_{30}$ film, which was annealed at $750^{\circ} \mathrm{C}$. The average grain size of FePt grains in this film is about $60 \mathrm{~nm}$. For the pure FePt film, it was found in previous study that the grain size already reaches $60 \mathrm{~nm}$ after annealing at much lower temperature $\left(600^{\circ} \mathrm{C}\right)$ with the same annealing time (30 min) [7]. This indicates that the AlN would restrain the growth of $\mathrm{FePt}$ grains. Fig. 4(b) reveals that the FePt grains in this film are FCT $\gamma_{1}$-FePt phase. Fig. 5 shows the TEM micrograph and electron diffraction pattern of the pure AlN film, which was annealed at $750^{\circ} \mathrm{C}$ for $30 \mathrm{~min}$ then ice-water quenched. It is confirmed that the AlN phase still maintains at amorphous state after annealing.

Fig. 6 shows the relations among in-plane coercivity $\left(H_{\mathrm{c} \|}\right)$, annealing temperature, and film thickness of the $(\mathrm{FePt})_{70}-(\mathrm{AlN})_{30}$ films. $H_{\mathrm{c} \|}$ is increased with annealing temperature to its optimum annealing temperature then decreased as the annealing temperature is further increased. The optimum annealing temperature means at which the maximum coercivity can be obtained. Maximum $H_{\mathrm{c} \|}$ values are about 2300, 4300, 5800, and 8000 Oe for $10,20,50$, and $100 \mathrm{~nm}$ films, 

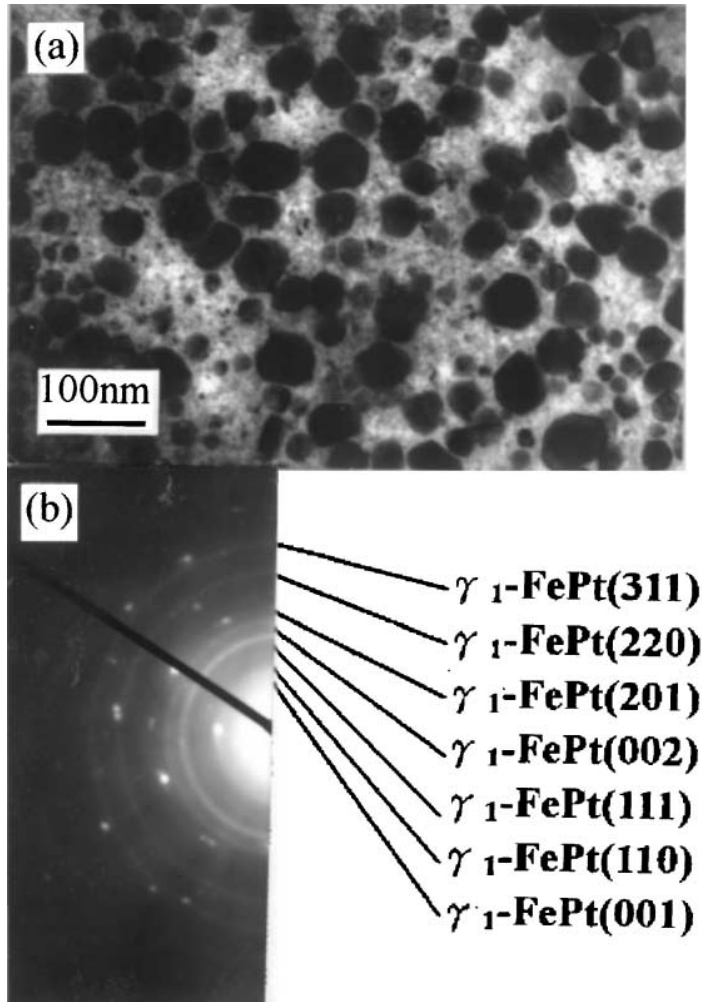

Fig. 4. Plane view TEM micrograph and electron diffraction pattern of the $(\mathrm{FePt})_{70}-(\mathrm{AlN})_{30}$ film which was annealed at $750^{\circ} \mathrm{C}$. (a) The bright field image and (b) the SAD pattern of the FePt grains in (a). The film thickness is $100 \mathrm{~nm}$.
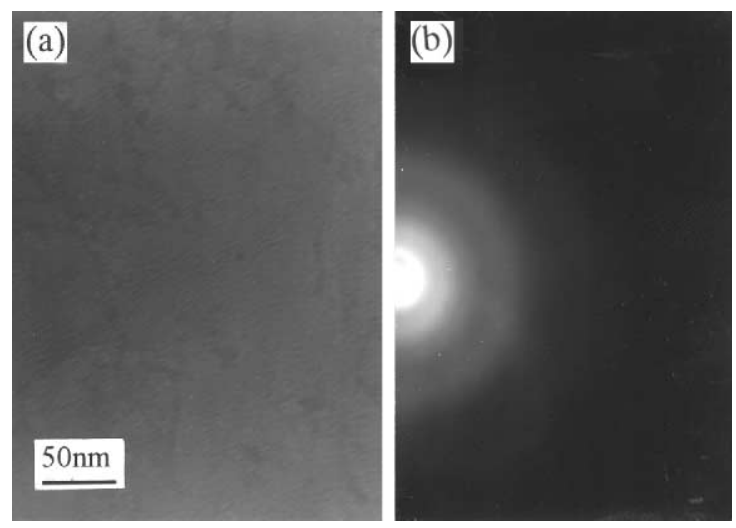

Fig. 5. TEM micrograph and electron diffraction pattern of the pure AIN film which was annealed at $750^{\circ} \mathrm{C}$ for $30 \mathrm{~min}$ then icewater quenched. (a) The bright field image and (b) the SAD pattern. The film thickness is $50 \mathrm{~nm}$.

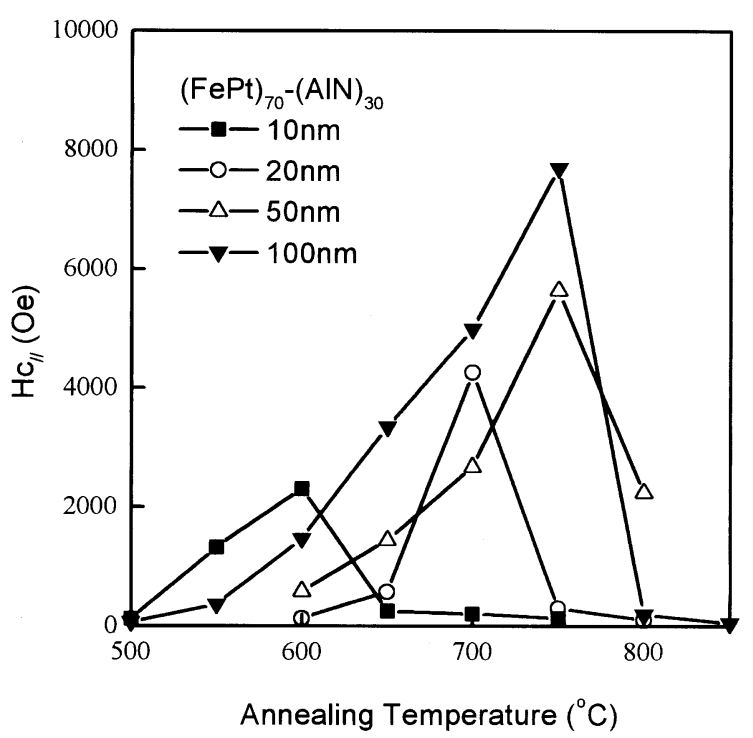

Fig. 6. Variations of $H_{\mathrm{c} \|}$ with annealing temperature of various $(\mathrm{FePt})_{70}-(\mathrm{AlN})_{30}$ films. Thicknesses of the films are 10, 20, 50, and $100 \mathrm{~nm}$, respectively.

respectively. The optimum annealing temperature is increased with increasing film thickness. The optimum annealing temperatures for the 10, 20, and $50 \mathrm{~nm}$ films are about $600^{\circ} \mathrm{C}, 700^{\circ} \mathrm{C}$ and $750^{\circ} \mathrm{C}$, respectively. AlN is a poor heat conductor and the amount of $\mathrm{AlN}$ is increased as temperature is increased with increasing film thickness, as shown in Fig. 6 . They are about $600^{\circ} \mathrm{C}, 700^{\circ} \mathrm{C}$ and $750^{\circ} \mathrm{C}$ for the 10,20 , and $50 \mathrm{~nm}$ films, respectively.

On the other hand, due to the amount of AlN in thinner film is less than that of thicker film, the ability to hinder the diffusion between $\mathrm{Si}$ substrate and the film is decreased for the thinner film. This is the reason why thinner film could not achieve high $H_{\mathrm{c} \|}$ even at higher annealing temperature. Maximum $H_{\mathrm{c} \|}$ values are about 2300, 4300, 5800, and $8000 \mathrm{Oe}$ for $10,20,50$, and $100 \mathrm{~nm}$ films, respectively, as shown in Fig. 6.

Fig. 7 shows the variation of $H_{\mathrm{c} \|}$, out-plane coercivity $\left(H_{\mathrm{c} \perp}\right)$, and the optimum annealing temperature with $\mathrm{AlN}$ vol\% of the FePt-AlN films. We can see that the optimum annealing temperature is increased with increasing AlN vol $\%$. The annealed film has maximum coercivity 


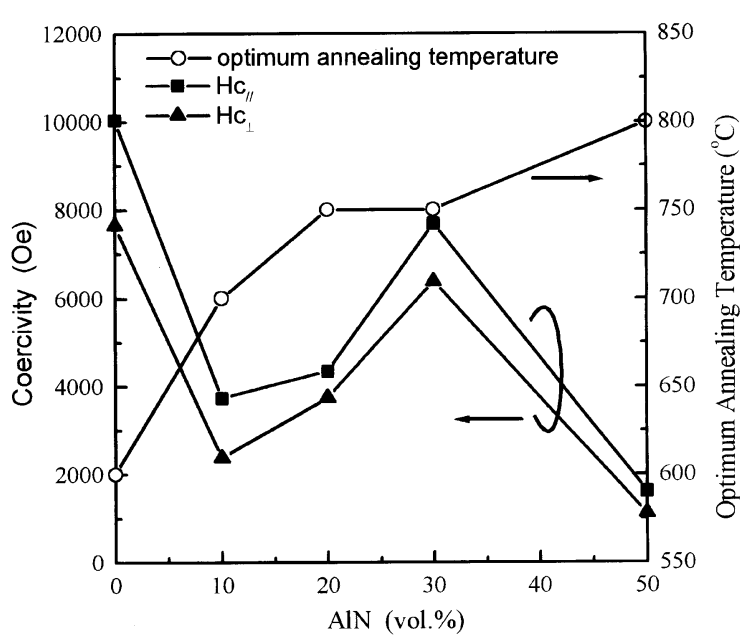

Fig. 7. Variations of $H_{\mathrm{c} \|}, H_{\mathrm{c} \perp}$, and the optimum annealing temperature with $\mathrm{AlN}$ vol\% of the FePt-AlN films. The film thickness is $100 \mathrm{~nm}$.

at optimum annealing temperature is mainly due to that the amount of hard $\gamma_{1}$-FePt phase in the film reaches its maximum value. The optimum annealing temperature of pure FePt film is about $600^{\circ} \mathrm{C}$. As AlN content is increased to $30 \mathrm{vol} \%$, the optimum annealing temperature increases to about $750^{\circ} \mathrm{C}$. This verifies that the increase of $\mathrm{AlN}$ content increases the phase transformation temperature of $\gamma-\mathrm{FePt} \rightarrow \gamma_{1}-\mathrm{FePt}$ again. The maximum $H_{\mathrm{c} \|}$ and $H_{\mathrm{c} \perp}$ of the pure FePt film can reach to about 10 and $7.8 \mathrm{kOe}$, respectively. These coercivities of the FePt-AlN films are all smaller than the coercivities of pure FePt film. The maximum $H_{\mathrm{c} \|}$ and $H_{\mathrm{c} \perp}$ of the $(\mathrm{FePt})_{70^{-}}-(\mathrm{AlN})_{30}$ film are only about 8 and $6 \mathrm{kOe}$, respectively. We suggest it is due to the quenching rate of $\mathrm{FePt}$ grains is decreased as AlN is added, so the $\gamma-\mathrm{FePt} \rightarrow \gamma_{1}$ $\mathrm{FePt}$ phase transformation in FePt-AlN film is less complete than that of pure FePt film. Since, the predominant factor to the $H_{\mathrm{c}}$ value of the film is the content of $\gamma_{1}$-FePt phase.

$H_{\mathrm{c} \perp}$ value of the FePt-AlN film is always lower than its $H_{\mathrm{c} \|}$ for the same AlN content, as shown in Fig. 7. Magnetic anisotropy of all the films is parallel to the film plane. The variation of maximum coercivity with AlN contents is irregular. Since a lot of factors would affect the film's coercivity, such as particle size, internal stress between FePt particles and surrounding AlN, chemical diffusion between Si substrate and film, etc.

Fig. 8 shows the relation between average grain size and annealing temperature of pure FePt film and $(\mathrm{FePt})_{70}-(\mathrm{AlN})_{30}$ films. The film thickness of these two $(\mathrm{FePt})_{70}-(\mathrm{AlN})_{30}$ films are 10 and $100 \mathrm{~nm}$. We can see that the grain size of FePt is increased rapidly with increasing annealing temperature. For the same annealing temperature and film thickness, the grain size of $(\mathrm{FePt})_{70}-(\mathrm{AlN})_{30}$ film is smaller than that of pure FePt film. This is owing to the grain growth of FePt is constrained by the surrounding $\mathrm{AlN}$ in $(\mathrm{FePt})_{70}-(\mathrm{AlN})_{30}$ film.

The film thickness would also restrain the grain growth. Grain size of the $10 \mathrm{~nm}(\mathrm{FePt})_{70}-(\mathrm{AlN})_{30}$ film is much smaller than that of the $100 \mathrm{~nm}$ film at the same annealing temperature. After annealing at $750^{\circ} \mathrm{C}$, the average grain size of the $100 \mathrm{~nm}$ $(\mathrm{FePt})_{70}-(\mathrm{AlN})_{30}$ film grows from $5 \mathrm{~nm}$ to about $60 \mathrm{~nm}$ but it only grows to about $20 \mathrm{~nm}$ for $10 \mathrm{~nm}$ $(\mathrm{FePt})_{70}-(\mathrm{AlN})_{30}$ film.

Fig. 9 shows the relation among $H_{\mathrm{c} \|}$, applied magnetic field $\left(H_{\mathrm{a}}\right)$, and AlN content of various

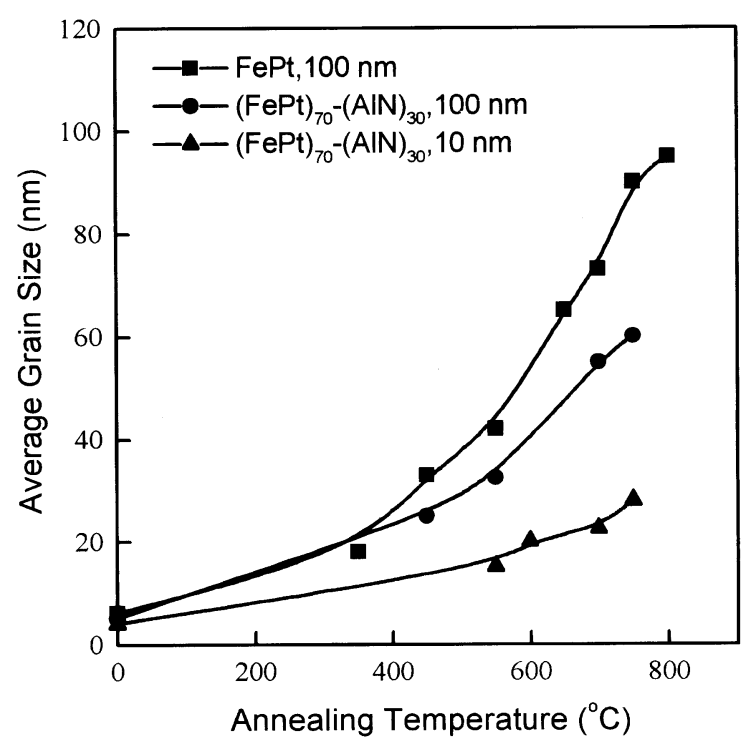

Fig. 8. Variation of the average grain size with annealing temperature of the pure $\mathrm{FePt}$ and $(\mathrm{FePt})_{70}-(\mathrm{AlN})_{30}$ films. Thicknesses of the films are 10 and $100 \mathrm{~nm}$. 


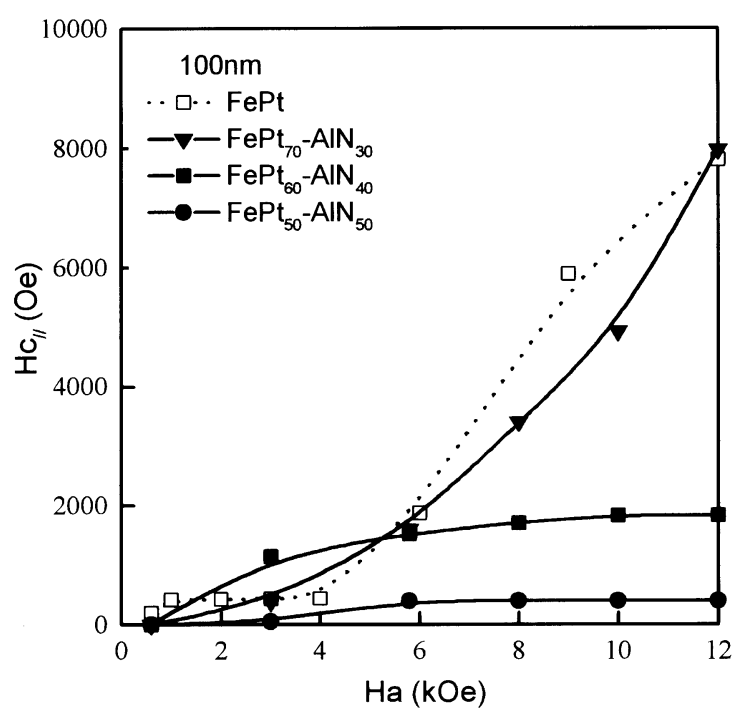

Fig. 9. $H_{\mathrm{c} \|}$ vs $H_{\mathrm{a}}$ of various annealed FePt-AlN films. AlN contents of these films are $0,30,40$, and $50 \mathrm{vol} \%$, respectively. These $H_{\mathrm{c} \|}$ are obtained from VSM minor loops. Dashed line is the $H_{\mathrm{c} \|}$ of the pure FePt film. These films are annealed at $750^{\circ} \mathrm{C}$ and the film thickness is $100 \mathrm{~nm}$.

FePt-AlN films which annealed at $750^{\circ} \mathrm{C}$. The $H_{\mathrm{c} \|}$ values are obtained from the minor loops of the VSM measurement, where the maximum $H_{\mathrm{a}}$ is $12 \mathrm{kOe}$. We can see that domain wall pinning mechanism [8] dominates as AlN content is less than $30 \mathrm{vol} \%$. However, the magnetic hardening mechanism gradually transfers to the domain wall nucleation as the AlN content increases further. As AlN content is higher than $40 \mathrm{vol} \%$, the magnetic hardening mechanism is domain wall nucleation. Since AIN is a poor heat conductor, harder to dissipate heat in the cooling process, so, more perfect FCT $\gamma_{1}-\mathrm{FePt}$ phase is obtained and the number of pinning sites (e.g., antiphase boundaries and various orientations of $\gamma_{1}$-FePt twin's interfaces [9]) is decreased as AlN content is increased.

$\delta M$ curves of the pure $\mathrm{FePt},(\mathrm{FePt})_{70^{-}}(\mathrm{AlN})_{30}$, and $(\mathrm{FePt})_{60}-(\mathrm{AlN})_{40}$ films are shown in Fig. 10. According to Mayo et al. [10], the inter-grain interactions are exchange interactions when $\delta M$ is positive and the interactions are dipolar interactions as $\delta M$ is negative. We found that the exchange coupling was reduced as AIN content increased. As AlN content higher than $30 \mathrm{vol} \%$, only dipole interactions are observed. Fig. 10

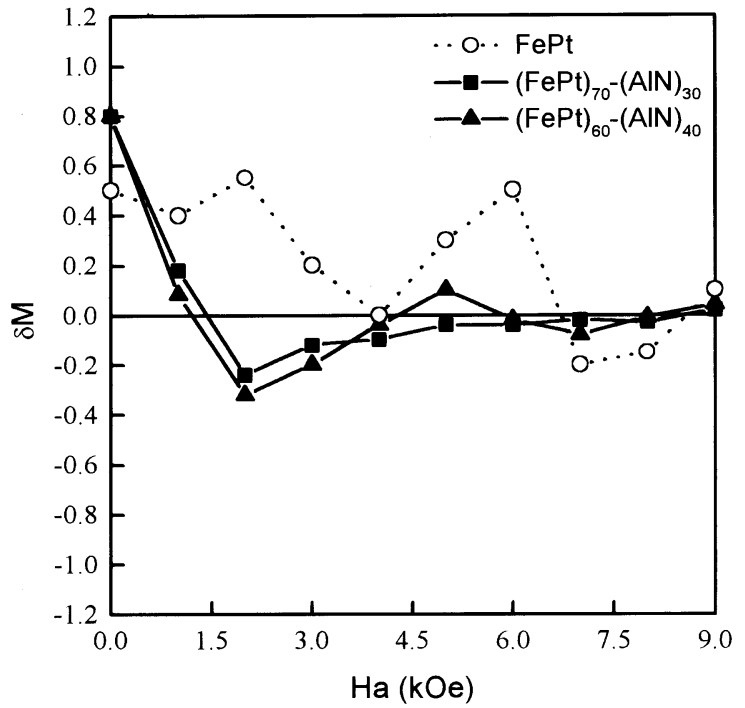

Fig. 10. $\delta M$ plots of various annealed FePt-AlN films. AlN contents of these films are 0,30 , and $40 \mathrm{vol} \%$, respectively. These films are annealed at $750^{\circ} \mathrm{C}$ and the film thickness is $100 \mathrm{~nm}$.

shows that the $\delta M$ is positive for pure FePt film and it is negative for 30 and $40 \mathrm{vol} \%$ AlN films. This indicates that $\mathrm{AlN}$ addition could reduce media noises of the FePt recording film.

\section{Conclusion}

We have successfully prepared high coercivity granular FePt-AlN films consisting of hard magnetic $\gamma_{1}-\mathrm{FePt}$ nanoparticles embedded in amorphous AlN matrix. The increase of AlN content will increase the phase transformation temperature of $\gamma$-FePt $\rightarrow \gamma_{1}$-FePt. We can adjust the coercivity and grain size of FePt-AlN nanocomposite films by controlling the film thickness, annealing temperature, and AIN content. The grain size increases with increasing annealing temperature and film thickness but decreased with increasing AlN content. The in-plane coercivity of the annealed FePt-AlN film was larger than outplane coercivity. A large in-plane coercivity of $8 \mathrm{kOe}$ was obtained for the $(\mathrm{FePt})_{70}-(\mathrm{AlN})_{30}$ film with thickness of $100 \mathrm{~nm}$ after annealing at $750^{\circ} \mathrm{C}$ for $30 \mathrm{~min}$. 


\section{Acknowledgements}

This work was supported by the National Science Council of ROC through Grant No. NSC 89-2216-E-002-053.

\section{References}

[1] M. Yu, Y. Liu, D.J. Sellmyer, J. Appl. Phys. 87 (2000) 6959.

[2] I. Kaitsu, A. Inomata, I. Okamoto, M. Shinohara, IEEE Trans. Magn. MAG-34 (1998) 1591.

[3] K. Ichihara, A. Kikitsu, K. Yusu, F. Nakamura, H. Ogiwara, IEEE Trans. Magn. MAG-34 (1998) 1603.
[4] J.N. Zhou, J. Du, A.F. Khapikov, S. Wang, J.A. Barnard, J.W. Harrell, W.D. Doyle, J. Appl. Phys. 87 (2000) 5624.

[5] C.P. Luo, S.H. Liou, D.J. Sellmyer, J. Appl. Phys. 87 (2000) 6941.

[6] J.A. Christodoulides, Y. Huang, Y. Zhang, G.C. Hadjipanayis, I. Panagiotopoulos, D. Niarchos, J. Appl. Phys. 87 (2000) 6938.

[7] P.C. Kuo, Y.D. Yao, C.M. Kuo, H.C. Wu, J. Appl. Phys. 87 (2000) 6146.

[8] G.C. Hadjipanayis, A. Kim, J. Appl. Phys. 63 (1988) 3310.

[9] Y. Tanaka, N. Kimura, K. Hono, K. Yasuda, T. Sakurai, J. Magn. Magn. Mater. 170 (1997) 289.

[10] P.I. Mayo, K. O’Grady, P.E. Kelly, J. Cambridge, J. Appl. Phys. 69 (1991) 4733. 